\title{
A tryptophan derivative, ITE, enhances liver cell metabolic functions in vitro
}

\author{
XIAOQIAN ZHANG ${ }^{*}$, JUAN LU ${ }^{1 *}$, BIN HE $^{2}$, LINGLING TANG ${ }^{1}$, XIAOLI LIU ${ }^{1}$, DANHUA ZHU ${ }^{1}$, \\ HONGCUI CAO ${ }^{1}$, YINGJIE WANG ${ }^{1}$ and LANJUAN LI ${ }^{1}$
}

\begin{abstract}
${ }^{1}$ State Key Laboratory for Diagnosis and Treatment of Infectious Diseases, Collaborative Innovation Center for Diagnosis and Treatment of Infectious Diseases, The First Affiliated Hospital, School of Medicine, Zhejiang University;

${ }^{2}$ Division of Hepatobiliary and Pancreatic Surgery, Department of Surgery, The First Affiliated Hospital,

School of Medicine, Zhejiang University; Key Laboratory of Combined Multi-Organ Transplantation, Ministry of Public Health, Hangzhou, Zhejiang 310003, P.R. China
\end{abstract}

Received August 27, 2016; Accepted December 5, 2016

DOI: $10.3892 /$ ijmm.2016.2825

\begin{abstract}
Cell encapsulation provides a three-dimensional support by incorporating isolated cells into microcapsules with the goal of simultaneously maintaining cell survival and function, as well as providing active transport for a bioreactor in vitro similarly to that observed in vivo. However, the biotransformation and metabolic functions of the encapsulated cells are not satisfactory for clinical applications. For this purpose, in this study, hepatoma-derived Huh7 cells/C3A cells were treated with 2-(1'H-indole-3'-carbonyl)-thiazole-4-carboxylic acid methyl ester (ITE), an endogenous non-toxic ligand for aryl hydrocarbon receptor, in monolayer cultures and on microspheres. The mRNA and protein levels, as well as the metabolic activities of drug metabolizing enzymes, albumin secretion and urea synthesis were determined. When the Huh7 and C3A cells cultured in a monolayer on two-dimensional surfaces, ITE enhanced the protein levels and the metabolic activities of the major cytochrome P450 (CYP450) enzymes, CYP1A1, CYP1A2, CYP3A4 and CYP1B1, and slightly increased albumin secretion and urea synthesis. Moreover, when cultured on microspheres, ITE also substantially increased the protein levels and metabolic activities of CYP1A1, CYP1A2, CYP3A4 and CYP1B1 in both liver cell lines. On the whole, our findings indicate that ITE enhances the enzymatic activities of major CYP450 enzymes and the metabolic functions of liver cells cultured in monolayer
\end{abstract}

Correspondence to: Professor Yingjie Wang or Professor Lanjuan Li, State Key Laboratory for Diagnosis and Treatment of Infectious Diseases, Collaborative Innovation Center for Diagnosis and Treatment of Infectious Diseases, The First Affiliated Hospital, School of Medicine, Zhejiang University, 79 Qingchun Road, Hangzhou, Zhejiang 310003, P.R. China

E-mail: yingjiewang@zju.edu.cn

E-mail: ljli@zju.edu.cn

${ }^{*}$ Contributed equally

Key words: 2-(1'H-indole-3'-carbonyl)-thiazole-4-carboxylic acid methyl ester, microspheres, cytochrome P450, metabolic functions or on microspheres, indicating that it may be utilized to improve the functions of hepatocytes. Thus, it may be used in the future for the treatment of liver diseases.

\section{Introduction}

The liver plays a central role in drug metabolism and detoxification. Acute liver failure (ALF) can lead to sudden death, mostly due to hepatic encephalopathy (HE), intracranial hypertension, multiple organ failure and sepsis (1). Due to the shortage of liver donors for transplantation, non-bioartificial liver (NBAL) and bioartificial liver (BAL) devices have been used either as a bridge to transplantation, allowing a more efficient utilization of available donor organs, or to 'buy time' for a patient's own liver to recover, reducing the high demand for donor organs (2). Many new companies have been formed in an attempt to profit from NBAL development and have recently made promising progress (3). However, the inability to mimic the biotransformation and metabolic functions of liver cells in vitro is a common disadvantage of NBAL devices. By contrast, by incorporating metabolically-active liver cells which can efficiently biotransform toxic substances and allow self-recovery and regeneration, BAL devices are likely to be a better alternative for the treatment of ALF (4).

Potential BAL cell sources include primary porcine hepatocytes, established hepatic cell-lines and primary human hepatocytes. Unfortunately, all cell types tested and cultured in vitro have failed to reach the same functionality observed in primary human hepatocytes (5). Since liver-specific functions and the proliferation of primary hepatocytes are rapidly lost during culture (6), hepatoma or hepatocellular carcinoma (HCC)-derived cell lines also need to be dramatically manipulated to retain liver-specific functions and safety-related requirements (5). In particular, established cell lines originated from hepatic tumors are known to lack a substantial set of liver-specific functions. For example, the expression levels of cytochrome P450 (CYP450s) are very low or even undetectable (7). Therefore, it has been a challenge to maintain viable and functional hepatocytes for extended periods of time (8-10). C3A, a subclone of the hepatoma- 
derived HepG2 cell line, is considered to be a suitable cell source for the study of bioartificial liver systems, due to its well-characterized cellular and biochemical properties and well-preserved hepatic functions (11), and Huh7, a commercially available human hepatoma cell line, is frequently used as an in vitro system to study hepatotoxicity (12). Since C3A cells possess a better differentiated hepatic phenotype, the cell line has already been used in one of the most developed BALs currently under research (13-15). Therefore, we primarily employed these cell lines in order to perform our experiments in this study.

In this study, to address the in vitro culture challenges, we developed a novel culture method by introducing 2-(1'H-indole3'-carbonyl)-thiazole-4-carboxylic acid methyl ester (ITE), a tryptophan derivative that acts as an endogenous aryl hydrocarbon receptor (AhR) ligand (16), into the culture medium. $\mathrm{AhR}$ is a transcription factor that increases xenobiotic metabolism, histone modification and tumorigenesis (17). Due to its role in regulating drug detoxification in a diverse group of xenobiotics, including polychlorinated dioxins and dibenzofurans (18), AhR has been extensively studied as a ligand-specific nuclear receptor compared to other members of the basic helixloop-helix/PAS protein family (19). Among other functions, the role of AhR in regulating the expression of several isozymes of the CYP450 drug-metabolizing enzymes has been extensively studied (20). Furthermore, ITE isolated from porcine lung tissue (21), has been identified as a very potent endogenous agonist for AhR. In contrast to 2,3,7,8-tetrachlorodibenzo-pdioxin (TCDD), another potent but artificial ligand of AhR (20), ITE has no obvious toxicity as previously reported.

In this study, we examined the effects of culturing Huh7 and C3A cells with ITE on cell viability and metabolic functions using monolayer cell cultures and microspheres. This is, to the best of our knowledge, the first study of an in vitro culture system that enhances the metabolic functions of Huh7 and C3A cells without toxicity, which may improve the functions of hepatocytes and may thus be useful in the future for the treatment of liver diseases.

\section{Materials and methods}

Reagents and antibodies. ITE was a gift from Dr Jiasheng Song, (AhR Pharmaceuticals, Inc., Madison, WI,USA). Anti-CYP450 isoenzyme 1A1 antibody (ab126828), anti-CYP450 isoenzyme 1B1 antibody (ab33586), anti-CYP450 isoenzyme 1A2 antibody (ab56073), CYP3A4 antibody (ab135813), CYP3A5 antibody (ab108624), CYP2D6 antibody (ab62204), CYP2C9 antibody (ab150364) and CYP2E1 antibody (ab90564) were all purchased from Abcam (Cambridge, MA, USA).

Cell culture. All cell cultures were incubated in a humidified atmosphere at $37^{\circ} \mathrm{C}$ and $5 \% \mathrm{CO}_{2}$. The Huh7 and $\mathrm{C} 3 \mathrm{~A}$ cells (CRL-10741; ATCC, Manassas, VA, USA) were cultured in Dulbecco's modified Eagle's medium (DMEM) (12430; Gibco, Auckland, New Zealand) supplemented with $10 \%$ fetal bovine serum (FBS) (10099; Gibco Life Technologies, Grand Island, NY, USA) as well as $1 \%$ penicillin/streptomycin (Gibco). The cells were detached following incubation with $0.05 \%$ trypsin-EDTA (25300; Gibco), counted, and finally diluted to $3 \times 10^{6} / \mathrm{ml}$ with $2.0 \%$ alginate solution.
Cell treatment. ITE was dissolved in DMSO, serial 1,000X stock solutions in DMSO were prepared and 1:1,000 diluted with culture medium into final concentrations of $0.2,0.5$ and $1 \mu \mathrm{M}$, respectively. For the $0 \mu \mathrm{M}$ ITE control group, only the same volume of DMSO was added to the culture medium so that the final concentration of DMSO was also kept at $0.1 \%(\mathrm{v} / \mathrm{v})$. In most cases, the cells were treated with serially diluted ITE for 24 and $48 \mathrm{~h}$ with ITE being replenished everyday.

Alginate microsphere production. Alginate encapsulation was performed as previously described (5) with modifications. Briefly, the Huh7 and C3A cells were suspended in $2.0 \%$ sodium alginate solution (154 mM NaCl, $10 \mathrm{mM}$ HEPES, pH 7.4). Each mixture was sprayed at a flow rate of $9.5 \mathrm{ml} / \mathrm{min}$ through a $300 \mu \mathrm{m}$ nozzle using an electrostatic microencapsulator unit (Nisco Engineering AG, Zurich, Switzerland). The vibration frequency of the nozzle was kept at $0.30 \mathrm{kHz}$. The alginate droplets were collected in a calcium chloride gelation bath (154 mM NaCl, $10 \mathrm{mM}$ HEPES, $115 \mathrm{mM} \mathrm{CaCl}_{2}, \mathrm{pH} \mathrm{7.4),}$ followed by $10 \mathrm{~min}$ of gelling and normal saline washes for three times. Eventually, the Huh7 and the C3A microspheres with the designed $800 \mu \mathrm{m}$ diameter were produced.

MTT assay. Cell viability was determined by MTT assay (11465007001; Roche Diagnostics, Basel, Switzerland) according to the manufacturer's instructions. Briefly, the cells were cultured with $100 \mu \mathrm{l}$ of medium per well in 96-well microplates. Following the addition of $10 \mu \mathrm{l}$ of the MTT labeling reagent (final concentration, $0.5 \mathrm{mg} / \mathrm{ml}$ ) to each well, the plates were incubated for $4 \mathrm{~h}$ in a humidified atmosphere at $37^{\circ} \mathrm{C}$ and $5 \% \mathrm{CO}_{2}$. The plates were incubated overnight with $100 \mu \mathrm{l}$ of the solubilization solution in each well. For the formation of purple formazan crystals, proportional to the number of metabolically active viable cells, the absorbance was measured using a microplate reader (DTX880; Beckman Coulter, Inc., Brea, CA, USA) at a wavelength of $570 \mathrm{~nm}$.

Assessment of cell viability by confocal microscopy of fluorescein diacetate (FDA)/propidium iodide (PI)-stained cells. The microspheres were washed twice with DMEM medium without phenol red and then stained for 2 min with $5 \mathrm{mg} / \mathrm{ml} \mathrm{FDA}$ and $10 \mathrm{mg} / \mathrm{ml}$ PI in Opti-MEM medium without phenol red (Gibco-Invitrogen Life Technologies, Paisley, Scotland). The stained beads were washed twice with Opti-MEM medium and examined using a Bio-Rad Radiance 2100 confocal microscope (Bio-Rad Laboratories, Inc., Hertfordshire, UK). Images were captured and analyzed using LaserSharp 2000 software (Bio-Rad Laboratories, Inc.).

Metabolic activity assay of CYP450 enzymes. Various groups of cell culture models were used in our study that included: $2 \mathrm{D}$, cells were cultured in a dish in a routine two-dimensional manner; 3D, cells were encapsulated and cultured under static conditions; and 3D-F, cells were encapsulated and cultured in the fluidized bed bioreactor. CYP450 1A2, 3A4, 1A1 and 1B1 enzyme activity assays were carried out directly in 24 -well plates. The measurement of luciferase activity was performed with a P450-Glo CYP1A2 assay (V8422), a CYP3A4 assay (V9002), a CYP1A1 assay (V8752) and a CYP1B1 assay (V8762) (all from Promega, Madison, WI, USA). In brief, the cells were incubated 
at $37^{\circ} \mathrm{C}$ in Krebs-Henseleit buffer (K3753; Sigma-Aldrich, St. Louis, MO, USA) containing luciferin-1A2, fresh medium containing luciferin-IPA or luciferin-CEE. After 1 or $4 \mathrm{~h}$ of incubation, $50 \mu \mathrm{l}$ of buffer or culture medium from each well were passed to a 96-well opaque white plate by mixing with an equal volume of the luciferin detection reagent to initiate a luminescent reaction. After $20 \mathrm{~min}$ of shaking at room temperature, luminescence was measured using a microplate reader (DTX880; Beckman Coulter, Inc.).

Ureogenesis and albumin synthesis determination. After running the experiments, all media were collected and stored at $-80^{\circ} \mathrm{C}$. The urea concentration was measured using the urea assay kit (DIUR-500; Bioassay Systems LLC, Hayward, CA, USA). The albumin concentration was assayed with the human albumin ELISA quantitation set (E80-129; Bethyl Laboratories, Montgomery, TX, USA). All results were analyzed with CurveExpert 1.3 software and fitted with logistic model with $\mathrm{r} 2>0.99$.

Immunofluorescence microscopy. At day 2 of culture, the cells plated in 24-well plates were fixed with $90 \%$ ethanol and washed with saline. The fixed cells were incubated with the indicated primary antibodies followed by $2 \mathrm{U} / \mathrm{ml}$ of Alexa Fluor ${ }^{\circledR} 488$ AffiniPure Rabbit Anti-Goat IgG (H+L) (305-545-003; Jackson ImmunoResearch Laboratories, Inc., West Grove, PA, USA). The nuclei were stained with Hoechst 33342 (Hoechst 33342 Trihydrochloride, Trihydrate - FluoroPure ${ }^{\mathrm{TM}}$ Grade, H21492; Thermo Fisher Scientific, Inc., Waltham, MA, USA). The slides were incubated at room temperature in the dark for $20 \mathrm{~min}$, rinsed with saline, and mounted in Vectashield (Vector Laboratories, Peterborough, UK) prior to examination with a confocal microscope.

Western blot analysis. After washing 3 times with phosphate buffered saline (PBS), the cells were lysed in lysis buffer (no. 9803; Cell Signaling Technology, Inc., Danvers, MA, USA) containing protease inhibitors (Complete Protease Inhibitor Cocktail) and phosphatase inhibitors (PhosSTOP) (both from Roche Diagnostics). Protein concentrations were measured using the BCA assay kit (Thermo Fisher Scientific, Inc.). Proteins in the lysates were separated using SDS-PAGE and immunoblotted with respective antibodies.

Quantitative PCR ( $q P C R)$. The microspheres were dissolved in $55 \mathrm{mM}$ sodium citrate. After washing with PBS twice, RNA was extracted using the RNeasy Mini kit (15596026; Qiagen, Hilden, Germany) according to the manufacturer's instructions. cDNA was synthesized using oligo primers and a reverse transcription kit (037A; both from Takara Bio, Inc., Shiga, Japan). The Bio-Rad Universal SYBR Supermix (72-5121) was used to perform qPCR assays on a Bio-Rad Cycler (C1000) (both from Bio-Rad Laboratories, Inc., Hercules, CA, USA) with various sequences.

DNA microarray. Briefly, total RNA was extracted from the C3A cells treated with $0.2 \mu \mathrm{M}$ ITE using TRIzol reagent (Cat. no. 15596-108; Life Technologies, Carlsbad, CA, USA) following the manufacturer's instructions, and the RIN was tested to inspect RNA integrity using an Agilent Bioanalyzer 2100
(Agilent Technologies, Inc., Santa Clara, CA, USA). Qualified total RNA was further purified using the RNeasy micro kit (Cat. no. 74004) and the RNase-Free DNase Set (Cat. no. 79254) (both from Qiagen). Total RNA was amplified, labeled and purified using the GeneChip 3' IVT PLUS Reagent kit to obtain biotin-labeled cRNAs (Cat. no. 902416; Affymetrix, Inc., Santa Clara, CA, USA) following the manufacturer's instructions. Array hybridization and washes were performed using the GeneChip ${ }^{\circledR}$ Hybridization, Wash and Stain kit (Cat. no. 900720) in a hybridization oven 645 (Cat. no. 00-0331-220V) and Fluidics Station 450 (Cat. no. 00-0079) (all from Affymetrix, Inc.) according to the manufacturer's instructions.

Gene expression profiling was conducted by Shanghai Biotechnology Corporation using the Affymetrix PrimeView ${ }^{\mathrm{TM}}$ Human Gene Expression Array (Affymetrix, Inc.). All data were analyzed according to the manufacturer's instructions. Raw data originated from Affymetrix CEL files were normalized by RMA background correction and values were $\log 2$ transformed. Comparison of the data sets by the t-test showed that 1,472 of the total of 49,293 probe-sets $(2.99 \%)$ were differentially expressed (Ifold changes $\mid \geq 2$ ). In order to analyze the enrichment of P-values of each GO term, we used Fisher's exact test to calculate $\mathrm{P}$-values and $\mathrm{R}$ package stats to calculate FDR (q-value) by the BH method (www.r-project.org).

Statistical analysis. Statistical analysis was performed using the Student's t-test and one-way analysis of variance (ANOVA) with SPSS for Windows version 20.0 (SPSS, Inc., Chicago, IL, USA). Data from representative experiments are presented as the means \pm standard deviation (SD). Differences were considered statistically significant with a P-value $<0.05$. The experiments were repeated at least 2 to 3 times in duplicate or triplicate for each condition.

\section{Results}

Cytotoxicity of ITE on Huh7 and C3A cells. To explore the potential toxicity of ITE on Huh7 and C3A cells cultured in a monolayer, we examined cell viability and morphology in the presence or absence of ITE (Fig. 1). The use of ITE at a concentration of up to $1 \mu \mathrm{M}$ and treatment for $48 \mathrm{~h}$ did not affect the growth of the Huh7 cells. When the C3A cells were treated for $48 \mathrm{~h}$ with ITE at a concentration of $0.5 \mu \mathrm{M}$ and above, ITE slightly yet significantly inhibited the growth of the C3A cells (Fig. 1A). Phase contrast microscopy revealed that treatment with $0.2 \mu \mathrm{M}$ ITE for $48 \mathrm{~h}$ did not have marked effects on the general morphology of either the Huh7 or the C3A cells grown as monolayer cultures (Fig. 1B). As ITE was dissolved in DMSO, the control group ( $0 \mu \mathrm{M}$ ITE) control media thus also contained the same quantity of DMSO. Therefore, $0 \mu \mathrm{M}$ ITE as the control group was selected for the use in the experiments described below.

Liver-specific gene expression in Huh7 and C3A cells. Following a previous publication (22), we evaluated whether ITE in culture enhances the transcription of several selected metabolism-associated genes, including CYP450 phase I and II enzymes, nuclear receptors and specific proteins. We focused on comparing the expression profiles of Huh7 and C3A cells cultured with ITE versus normal culture (Fig. 2). Our results 

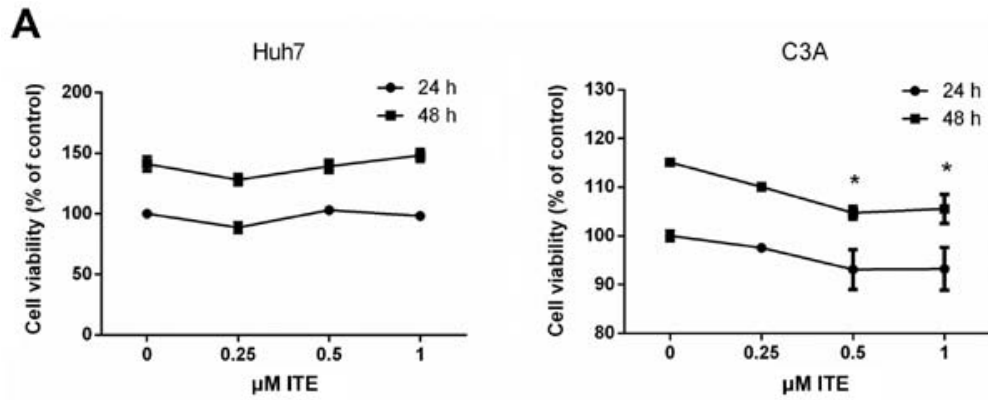

B

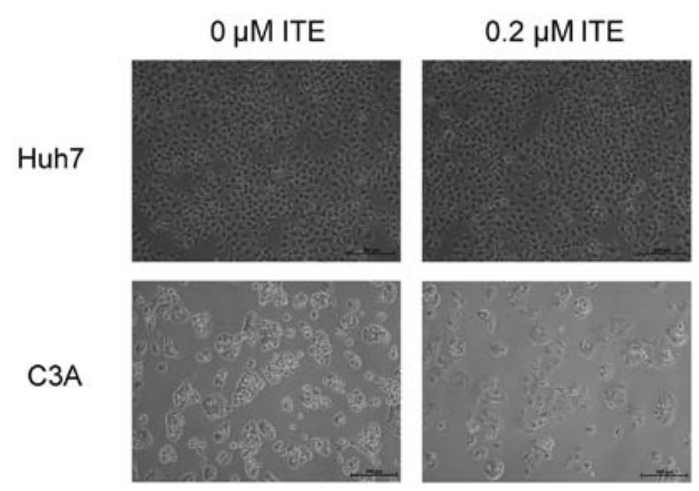

Figure 1. Analysis of the toxic effects of 2-(1'H-indole-3'-carbonyl)-thiazole-4-carboxylic acid methyl ester (ITE) on Huh7 and C3A cell viability and morphology. (A) Cell viability with or without increasing concentrations of ITE for 24 and $48 \mathrm{~h}$ was determined by MTT assay. "P $<0.05$ compared with the control group $(0 \mu \mathrm{M})$ ITE, $24 \mathrm{~h}$. (B) Phase contrast microscopy of Huh7 and C3A cells on monolayer cultures with or without $0.2 \mu \mathrm{M}$ ITE treatment for $48 \mathrm{~h}$.

A

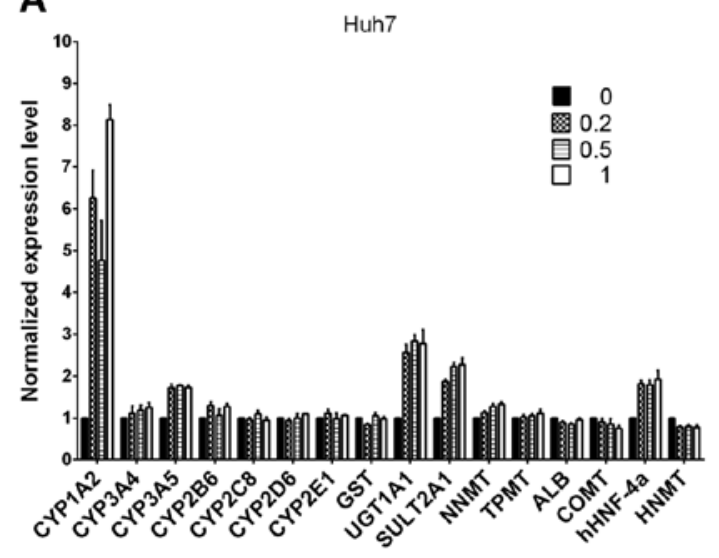

B

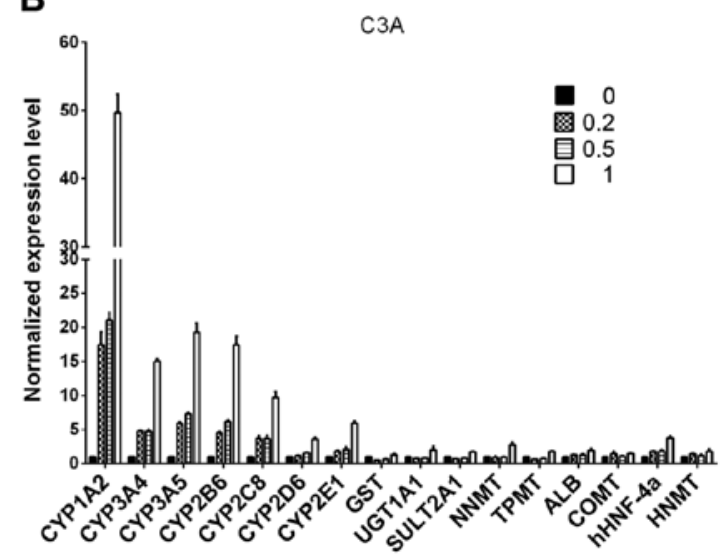

Figure 2. The mRNA levels of cytochrome P450 (CYP450s), phase II enzymes, nuclear receptors and specific proteins were analyzed by RT-qPCR for (A) Huh7 and (B) C3A cells on monolayer cultures treated with or without 2-(1'H-indole-3'-carbonyl)-thiazole-4-carboxylic acid methyl ester (ITE) for $48 \mathrm{~h}$. The values of 0,0.2, 0.5 , 1 indicate ITE molarity $0,0.2,0.5$ and $1 \mu \mathrm{M}$, respectively. UGT, UDP glycosyltransferase; SULT, sulfotransferase; COMT, catechol- $O$-methyltransferase; HNMT, histamine N-methyltransferase; NNMT, nicotinamide N-methyltransferase; CAR, constitutive androstane receptor; ALB, albumin; GST, glutathione S-transferase.

indicated that the transcription levels of some CYP450-related genes and nuclear receptors were elevated in the cultures containing ITE. After being exposed to ITE, the liver cells may modulate the CYP450-related genes of 1A2, 3A5, UGT1A1, SULT2A1 and nuclear receptors of hHNF-4a in Huh7 cells, and $1 \mathrm{~A} 2,3 \mathrm{~A} 4,3 \mathrm{~A} 5,2 \mathrm{~B} 6,2 \mathrm{C} 8,2 \mathrm{D} 6,2 \mathrm{E} 1$ and nuclear receptors gene of hHNF-4a in C3A cells.

CYP450 protein expression in Huh7 and C3A cells. We then measured the expression of proteins in the CYP450 system in the Huh7 and C3A cells. The CYP1A2, CYP3A4, CYP2E1, CYP1A1 and CYP1B1 protein levels were detected by western blot analysis. The protein levels of CYP3A4, CYP2E1 and
CYP1B1 were increased by varying degrees in the presence of $0.2 \mu \mathrm{M}$ ITE in the culture medium compared to the cells cultured in normal medium; however, CYP1A2 was not affected by ITE treatment (Fig. 3). Amongst the examined CYP450s, the protein levels of CYP3A4 markedly increased in accordance with the metabolic activities (shown below).

Metabolic functions of Huh7 and C3A cells. Metabolic functions were examined to assess the biotransformation and synthesis capacity of the Huh7 and C3A cells in the presence of ITE in culture (Fig. 4). As expected, the CYP450 activity levels (CYP1A1, CYP1A2, CYP1B1 and CYP3A4) were all significantly increased in the Huh7 and C3A cells cultured with 
A

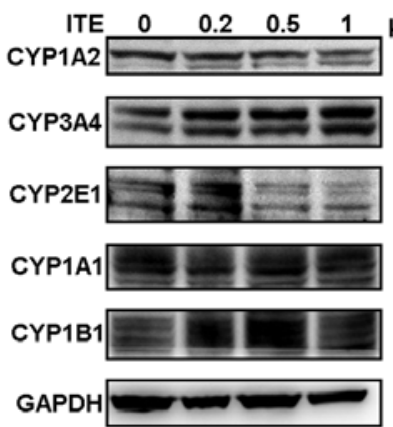

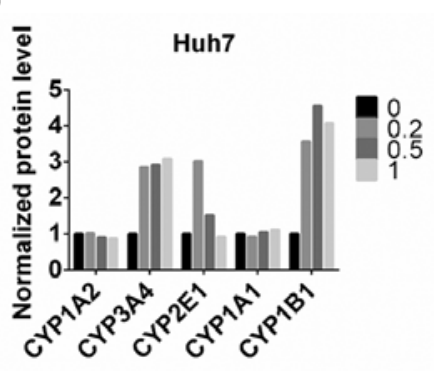

B

C3A

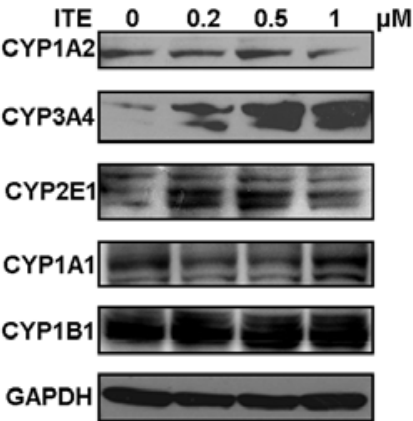

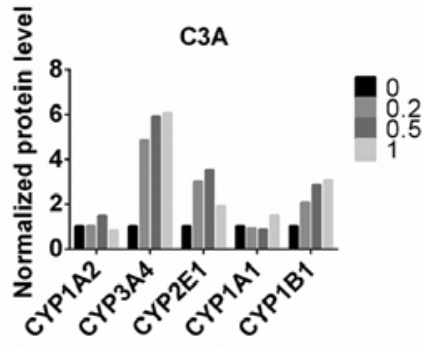

Figure 3. Cytochrome P450 (CYP450) protein expression was assessed by western blot analysis. (A and B) CYP450 protein expression in Huh7 and C3A cells on monolayer culture treated with various concentrations of 2-(1'H-indole-3'-carbonyl)-thiazole-4-carboxylic acid methyl ester (ITE) for 48 h determined by western blot analysis.

A

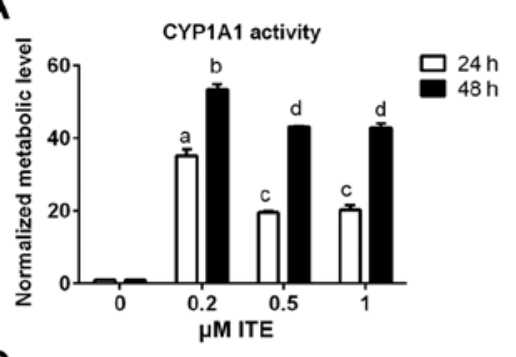

D

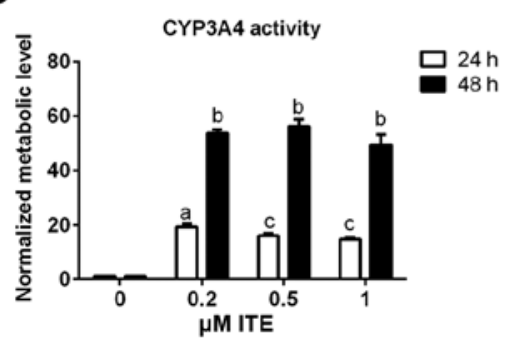

G

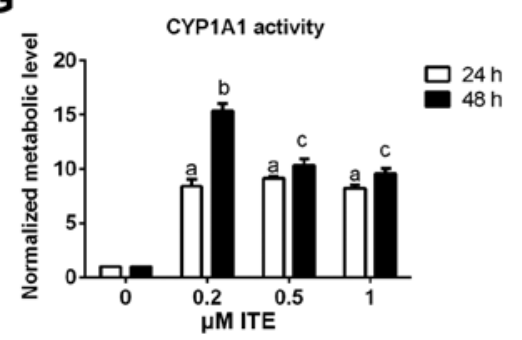

$\mathbf{J}$

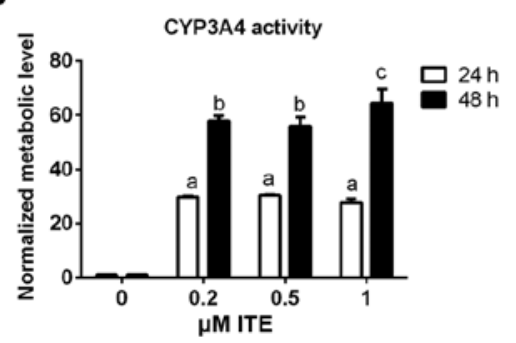

B

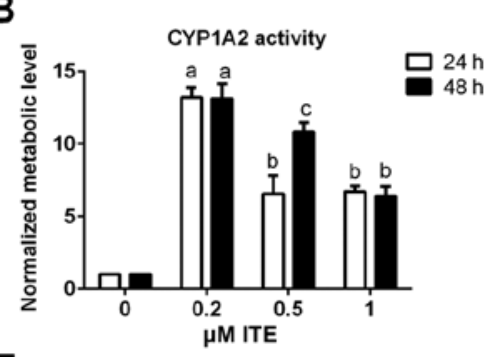

E

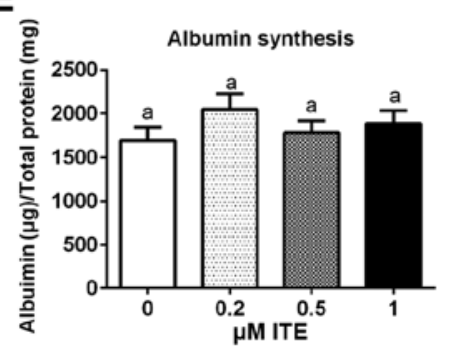

C3A

H
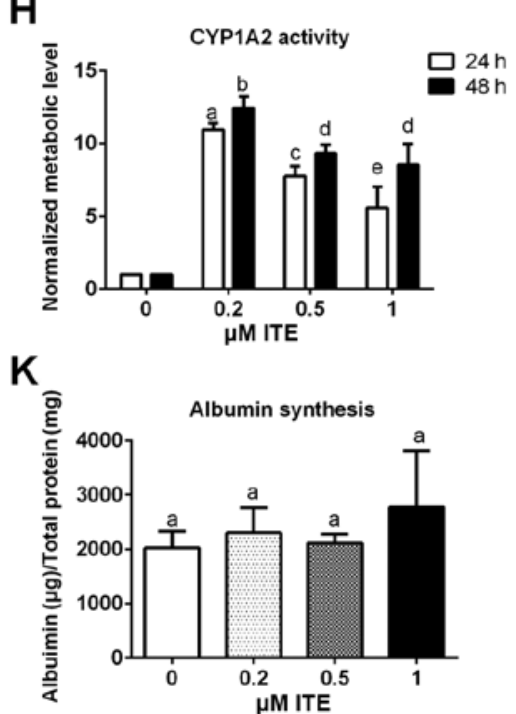

C

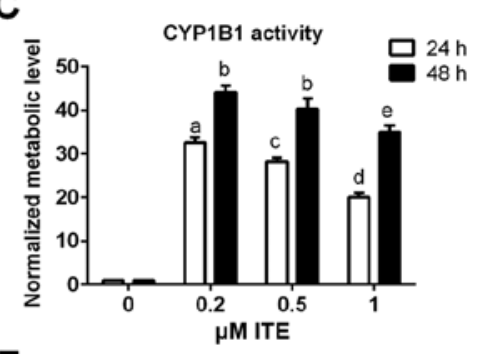

F

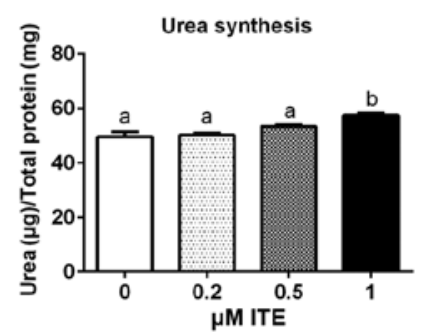

I

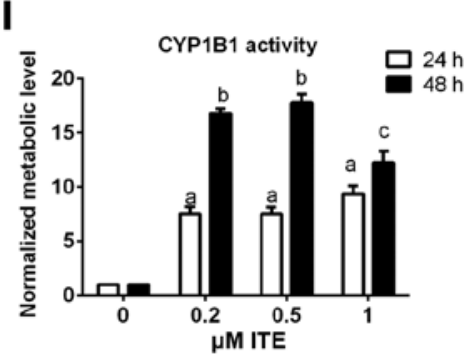

L

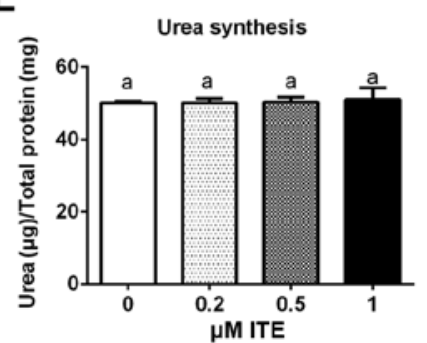

Figure 4. Determination of cytochrome P450 (CYP450) enzymatic activities and functionalities of Huh7 and C3A cells. Enzymatic activities of phase I enzymes (CYP1A2, CYP1A1, CYP1B1 and CYP3A4) and levels of albumin secretion and urea synthesis in (A-F) Huh7 cells and (G-L) C3A cells treated with various concentrations of 2-(1'H-indole-3'-carbonyl)-thiazole-4-carboxylic acid methyl ester (ITE) after $48 \mathrm{~h}$ was performed. The activities of phase I enzymes (CYP1A2, CYP1A1, CYP1B1 and CYP3A4) were measured using fluorometric substrates under different culture conditions. All data were normalized to the activity of $\mathrm{C} 3 \mathrm{~A}$ cells cultured in a dish. Columns labeled with the same letter indicate conditions not statistically significant; all other comparisons, $\mathrm{P}<0.05$. 


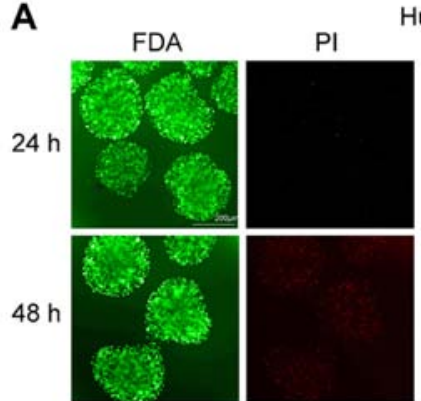

$0 \mu \mathrm{M}$ ITE
Huh7
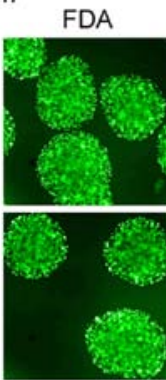

$1 \mu \mathrm{M}$ ITE
$\mathrm{PI}$

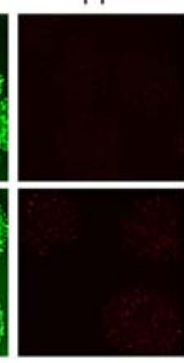

PI
B

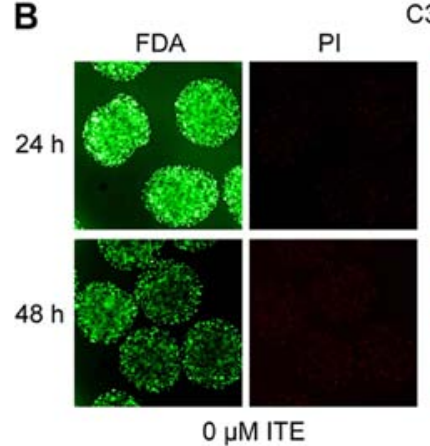

C3A

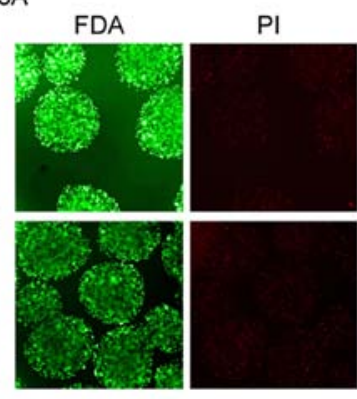

$1 \mu \mathrm{M}$ ITE

Figure 5. Viability and phase contrast microscopy of Huh7 and C3A cell microspheres encapsulated in alginate beads. (A) Phase and fluorescence microscopy images of Huh7 cells in microspheres with and without $1 \mu \mathrm{M} 2$-(1'H-indole-3'-carbonyl)-thiazole-4-carboxylic acid methyl ester (ITE) treatment for 24 and $48 \mathrm{~h}$. (B) Phase and fluorescence microscopy images of C3A cells in microspheres with and without $1 \mu \mathrm{M}$ ITE treatment for 24 and $48 \mathrm{~h}$. Scale bar, $200 \mu \mathrm{m}$. Living cells were stained in green CM-FDA, whereas dead cells were stained in red using propidium iodide (PI).

ITE. Of note, $0.2 \mu \mathrm{M}$ ITE was the optimal concentration for most CYP450s, but the activity of CYP3A4 in the C3A cells was higher at $1 \mu \mathrm{M}$ ITE (Fig. 4J). The changes in the kinetics of CYP450 activity in response to ITE treatment were different between Huh7 cells and C3A cells (Fig. 4A vs. C and G vs. I). In the Huh7 cells, the activities of both CYP1A1 and CYP1B1 reached the highest levels at $0.2 \mu \mathrm{M}$ ITE (Fig. 4A and C). By contrast, in the C3A cells (Fig. 4G and I), the activity of CYP1A1 reached the highest level at $0.2 \mu \mathrm{M}$ ITE and then decreased at 0.5 and $1 \mu \mathrm{M}$ ITE, while the activity of CYP1B1 kept increasing until $0.5 \mu \mathrm{M}$ ITE and then started to decrease at $1 \mu \mathrm{M}$ ITE. Amongst the four CYP450s examined, CYP3A4 exhibited the highest increase in metabolic activity in both cell lines (Fig. 4D and J). The enhancement of CYP450 activity levels indicate a higher detoxification capacity in liver cells maintained in our new culture condition. By contrast, albumin secretion (Fig. 4E and K) and urea synthesis (Fig. 4F and L), were only slightly increased by ITE under these conditions and did not reach statistical significance.

Toxic effect of ITE on Huh7 and C3A cells in alginate microspheres. To explore the potential toxic effect of ITE on Huh7 and $\mathrm{C} 3 \mathrm{~A}$ cells cultured in alginate microspheres, we determined the cellular morphology and viability in the presence or absence of ITE in culture (Fig. 5). The morphology of the Huh7 and C3A cells cultured in alginate microspheres was not affected by ITE, and viability measured by FDA/PI staining indicated that ITE $(0$ and $1 \mu \mathrm{M})$ was minimally toxic to the growth of cells in alginate microspheres.

Expression of liver-specific genes in Huh7 and C3A cells in alginate microspheres. To explore whether ITE was able to further improve the transcription of metabolism-associated genes in the Huh7 and C3A cells cultured in microspheres, we examined the transcription levels of CYP450-related genes. Our results revealed that ITE increased the mRNA expression levels of CYP450-related genes, such as 1A2, 2B6, 2D6, UGT1A1, SUL1A2 and nuclear receptor Hecbpa with a $>2$-fold increase compared with the control group in the Huh7 microspheres, and 1A2, UGT1A1, COMT and hHNF-4a in the C3A microspheres (Fig. 6).

CYP450 protein expression in Huh7 and C3A cells in alginate microspheres. The CYP450 protein levels were then measured in the Huh7 and C3A cells cultured in microspheres. The CYP1A2, CYP3A4, CYP2E1, CYP1A1 and CYP1B1 proteins were detected by western blot analysis, which confirmed that ITE increased the protein levels of CYP450 enzymes in both the Huh7 and C3A cells (Fig. 7). The CYP3A4 and CYP2E1
A

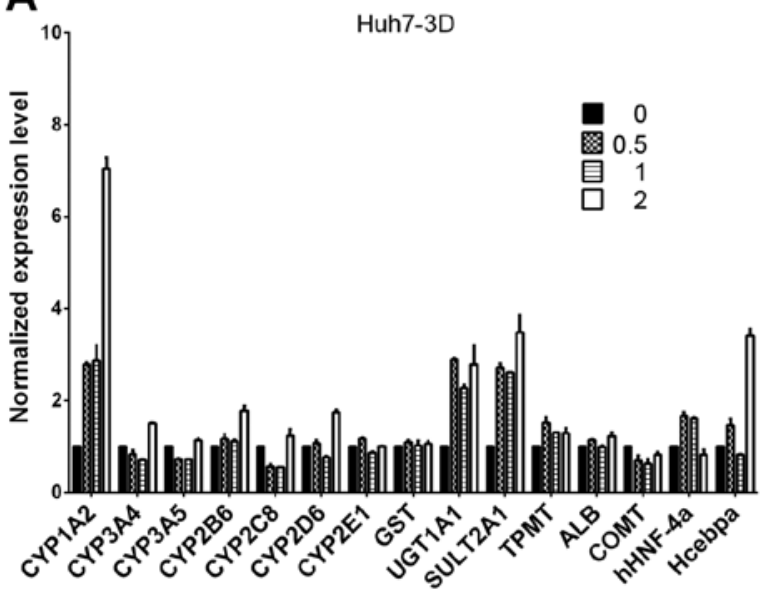

B

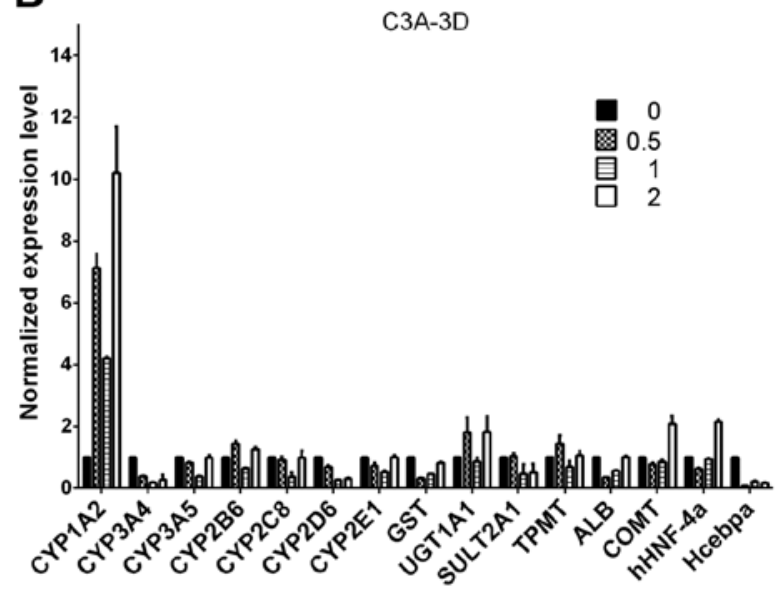

Figure 6. Gene expression of cytochrome P450 (CYP450), phase II enzymes, nuclear receptors and specific proteins in (A) Huh7-3D cells and (B) C3A-3D cells in microspheres with and without 2-(1'H-indole-3'-carbonyl)-thiazole-4-carboxylic acid methyl ester (ITE) treatment after $48 \mathrm{~h}$. 

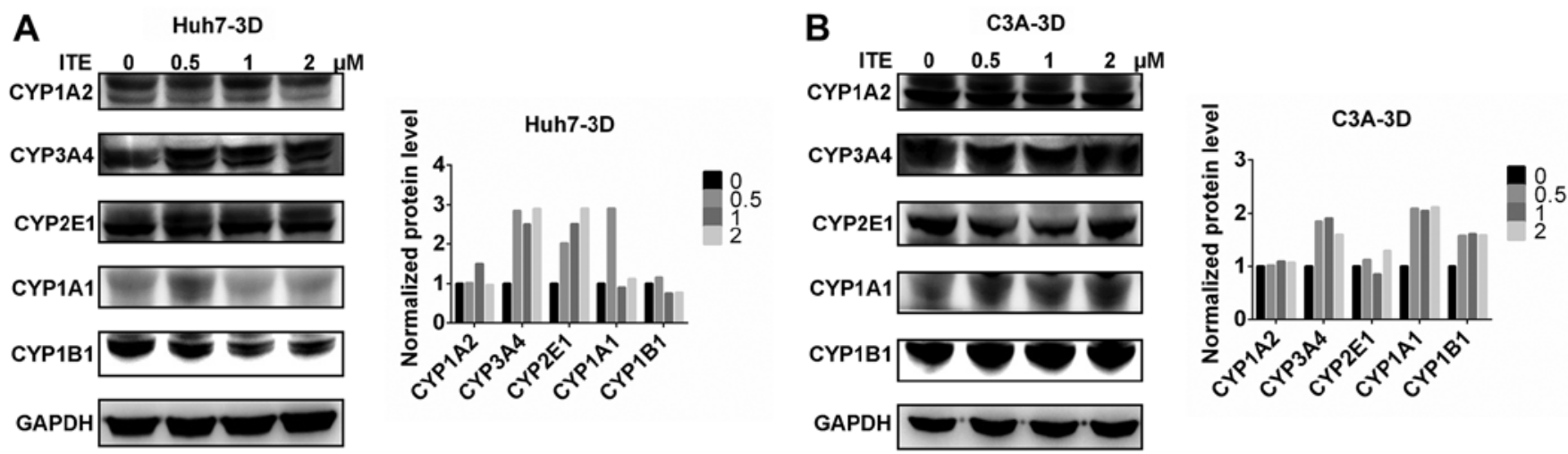

Figure 7. Cytochrome P450 (CYP450) protein levels were assessed by western blot analysis. (A and B) CYP450 protein levels of Huh7-3D and C3A-3D cells cultured in microspheres in the presence of various concentrations of 2-(1'H-indole-3'-carbonyl)-thiazole-4-carboxylic acid methyl ester (ITE) for $48 \mathrm{~h}$ were determined by western blot analysis.

A

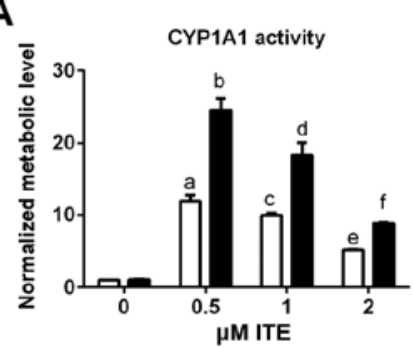

D

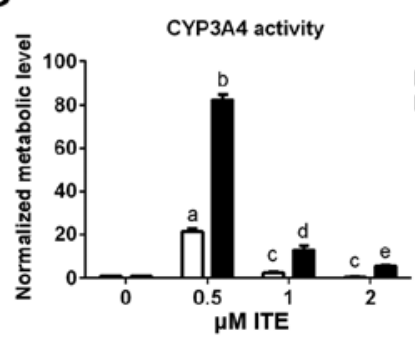

G

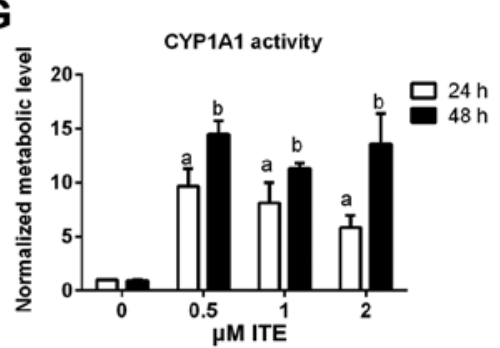

$\mathbf{J}$

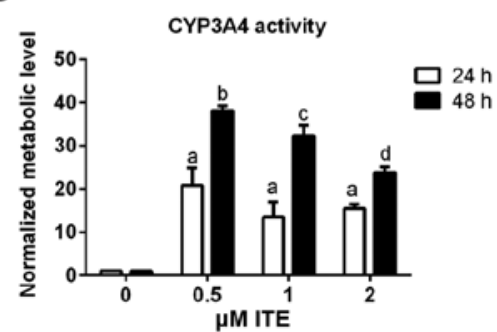

Huh7-3D

B

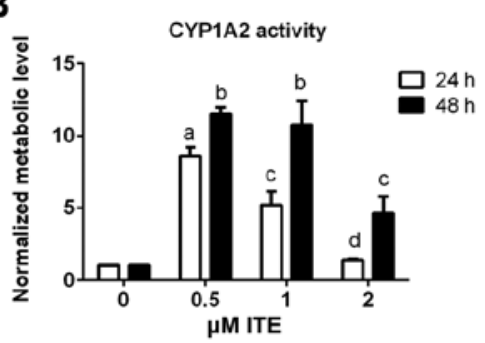

E

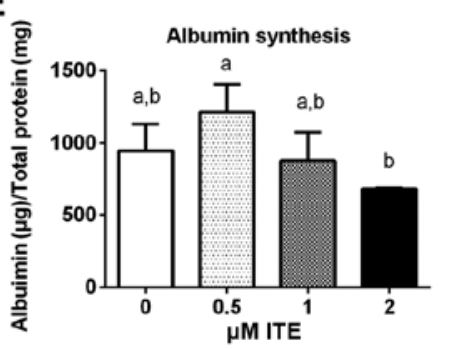

C3A-3D

H

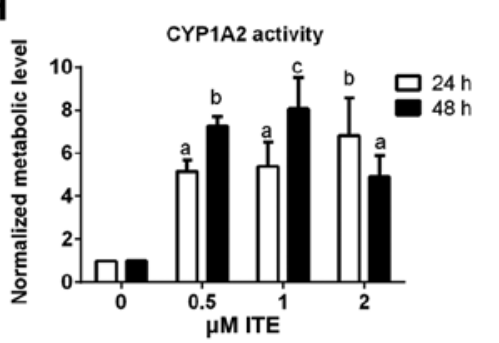

K

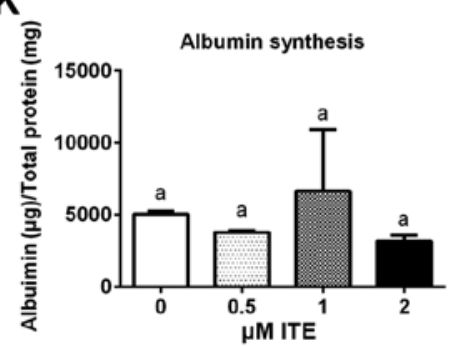

C

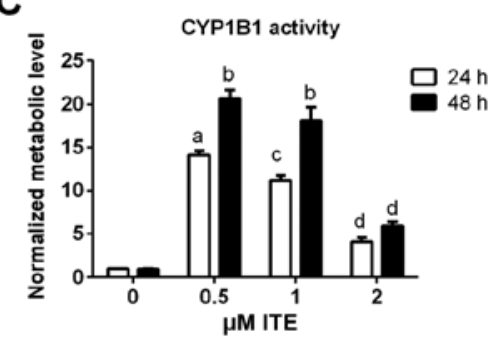

F

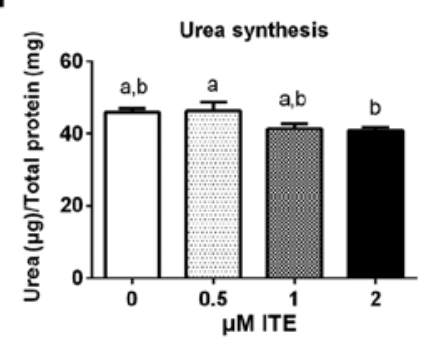

I

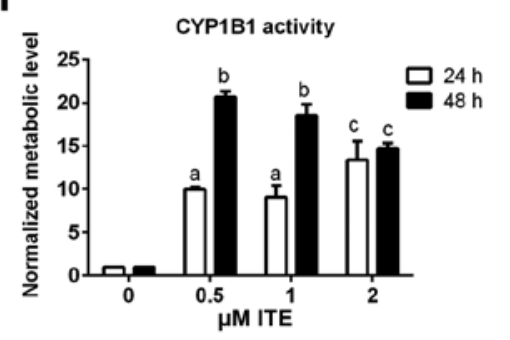

L

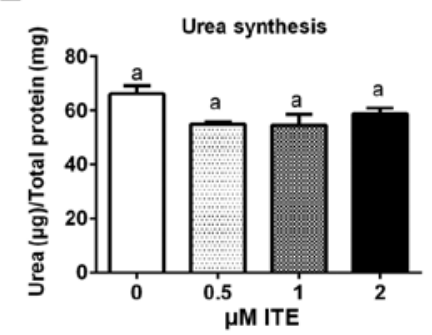

Figure 8. Determination of cytochrome P450 (CYP450) enzymatic activities and cell functionalities of Huh7-3D and C3A-3D cells. Enzymatic activities of phase I enzymes (CYP1A2, CYP1A1, CYP1B1 and CYP3A4) and the levels of albumin secretion and urea synthesis of (A-F) Huh7-3D cells and (G-L) C3A-3D cells cultured in microspheres with various concentrations of 2-(1'H-indole-3'-carbonyl)-thiazole-4-carboxylic acid methyl ester (ITE) after $48 \mathrm{~h}$ were performed. The activities of phase I enzymes (CYP1A2 and CYP3A4) were measured using fluorometric substrates under different culture conditions. All data were normalized to the activity of C3A-3D cells cultured in a dish. Columns labeled with the same letter indicate conditions not statistically different; all other comparisons, $\mathrm{P}<0.05$. 


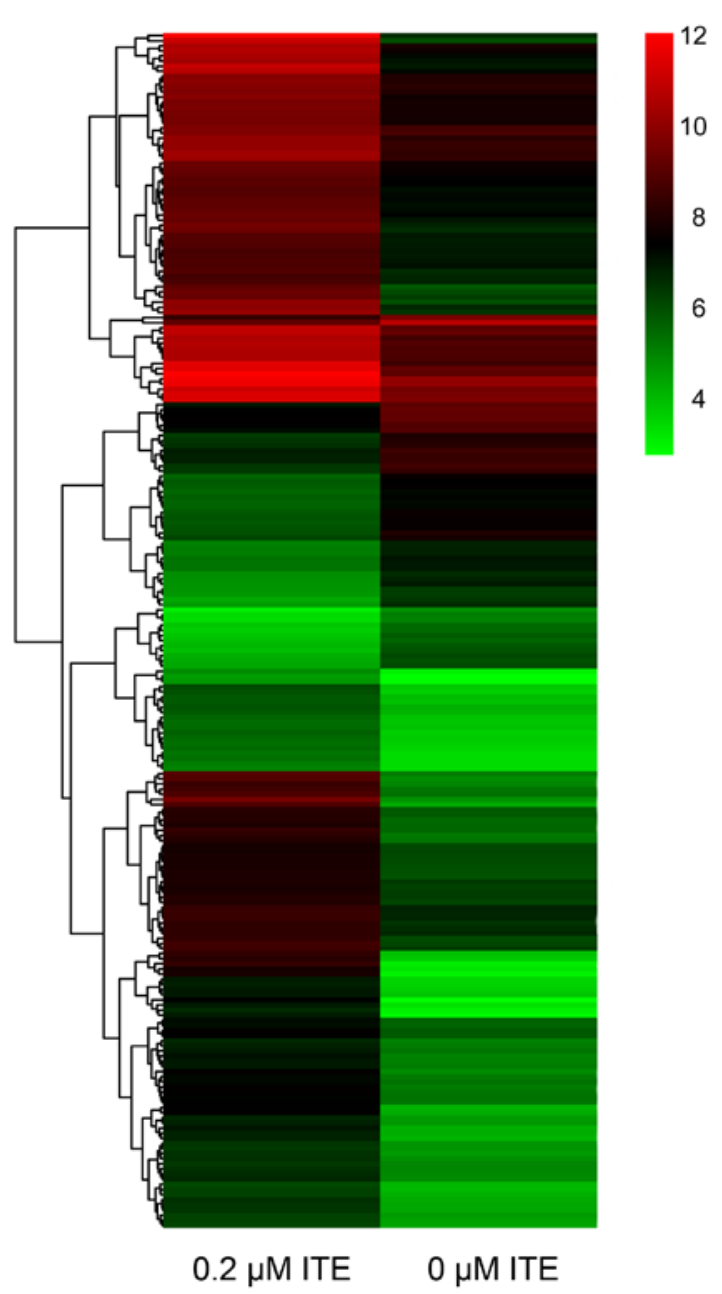

Figure 9. Heatmap for DNA microarray data on monolayer C3A cells treated with and without $0.2 \mu \mathrm{M} 2$-(1'H-indole-3'-carbonyl)-thiazole-4-carboxylic acid methyl ester (ITE) for $48 \mathrm{~h}$.

protein levels were increased by ITE treatment both in Huh7 microspheres and $\mathrm{C} 3 \mathrm{~A}$ microspheres. The CYP1A1 protein level in $\mathrm{C} 3 \mathrm{~A}$ microspheres was increased after ITE treatment. By contrast, in Huh7 microspheres, the CYP1A1 protein level was increased only with $0.5 \mu \mathrm{M}$ ITE, but decreased with 1 and $2 \mu \mathrm{M}$ ITE. However CYP1A2 and CYP1B1 were not affected by ITE, which was inconsistent with their metabolic activities (shown below). Again, amongst the examined CYP450s, the greatest increase was observed in the protein levels of CYP3A4.

Huh7 and C3A cell functions in alginate microspheres. We evaluated the metabolic functions and synthesis capacity of the Huh7 and C3A cells cultured in alginate microspheres in the presence of ITE (Fig. 8). As already demonstrated in Huh7 and $\mathrm{C} 3 \mathrm{~A}$ cells on monolayer cultures, the metabolic activities of the main CYP450s (CYP1A1, CYP1A2, CYP1B1 and CYP3A4) in the Huh7 and $\mathrm{C} 3 \mathrm{~A}$ cells cultured in alginate microspheres significantly increased with ITE treatment (Fig. 8A-D and G-J). In the $\mathrm{C} 3 \mathrm{~A}$ microspheres, albumin secretion and urea synthesis were not affected by ITE (Fig. 8K and L). However, albumin secretion and urea synthesis in the Huh7 microspheres seemed to be slightly affected. In contrast to $0.5 \mu \mathrm{M}$ ITE treatment which slightly increased the albumin secretion (Fig. 8E) and urea synthesis (Fig. 8F), higher concentrations (1 and $2 \mu \mathrm{M}$ ) of ITE decreased both albumin secretion (Fig. 8E) and urea synthesis (Fig. 8F). All these results indicated that ITE treatment led to significantly higher detoxification capacities of the liver cells, but had a lesser effect on their biological synthesis capabilities.

DNA microarray. In order to explore the transcriptional profile of ITE-treated Huh7 and C3A cells on monolayer cultures, we performed a DNA microarray. We found that the ITE-treated C3A cells elicited quite different transcriptional profiles compared to the untreated cells (Fig. 9). By contrast, $0.2 \mu \mathrm{M}$ ITE markedly altered processes involved in cell cycle, DNA replication and the metabolism of xenobiotics via the CYP450 system (Fig. 10). Moreover GO enrichment analysis further verified that processes, such as mitotic cell cycle, mitotic nuclear division and DNA replication were particularly altered by ITE treatment (Fig. 11), indicating a potential link between P450-mediated metabolism activities and cell cycle regulation.

\section{Discussion}

The liver plays many essential roles in maintaining normal physiology. Cell availability, the maintenance of cell viability and functionality are critical for the performance of various purposes, such as bioartificial liver and fundamental cell biology studies. It has been reported that the addition of low concentrations of dexamethasone to hormone-defined medium is beneficial for hepatocyte morphology, survival and liverspecific functions (23-25). Nevertheless, these approaches are not available in BAL design, as the continuous exposure of patients to these specialized and non-physiological media components poses major disadvantages (26). However, low concentrations of ITE, a natural ligand isolated from porcine lung tissue, has exhibited minimal toxicity (21). In this study, to the best of our knowledge, we report for the first time, that liver cells cultured in both monolayer or alginate microspheres in the presence of ITE exhibited a significant enhancement in the maintenance of hepatocyte metabolic functions without any marked toxicity. Hence, our approach may be an optimal alternative for the enhancement of the metabolic profile of $\mathrm{C} 3 \mathrm{~A}$ human-derived hepatocyte lines in order to be used, not only in BALs, but also in clinical trials.

The extensive use of humanliver cell lines eitherfrom tumoral origin or obtained by oncogenic immortalization is hindered by the loss of various liver-specific functions, particularly several CYP450-related enzyme activities (27). The CYP450 superfamily is involved in the metabolism of drugs, chemicals and endogenous substrates. Among the CYP450 family, CYP1A2 and CYP3A4 are frequently investigated in the human liver since they play essential roles in drug clearance (7). Since numerous toxic compounds accumulate in the circulation in patients with ALF, a properly functioning detoxification system is a prerequisite for a BAL (28). In addition, as previously demonstrated, the treatment of experimental ALF in dogs with bioreactors containing CYP3A4-overexpressing HepG2 cells improved survival compared to treatment with bioreactors containing only HepG2 cells (29). During the process of hepatic detoxification, which aims at the biotransformation of 


\section{$0.2 \mu \mathrm{M}$ ITE vs. $0 \mu \mathrm{M}$ ITE KEGG enrichment}

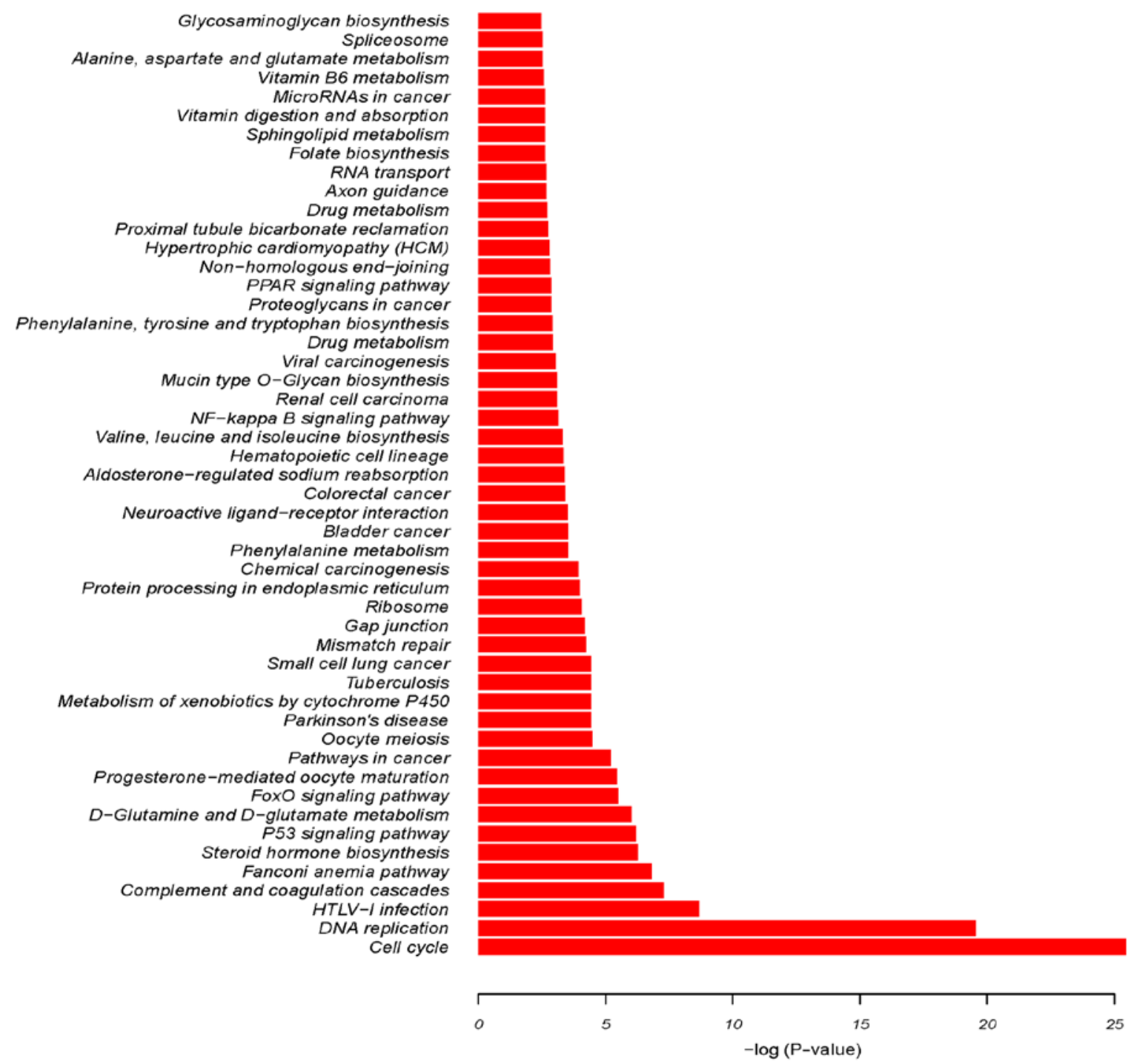

Figure 10. KEGG for DNA microarray data on monolayer C3A cells treated with and without $0.2 \mu \mathrm{M}$ 2-(1'H-indole-3'-carbonyl)-thiazole-4-carboxylic acid methyl ester (ITE) for $48 \mathrm{~h}$.

hydrophobic toxins into water-soluble substances, intracellular modification is specifically a hydroxylation reaction, conducted by the large family of CYPs (28). Moreover, among various factors involved in the regulation of hepatic detoxification, the nuclear receptors are significantly important. These include the AhR (dioxin), the hepatocyte nuclear factor $4 \alpha(\mathrm{HNF} 4 \alpha)$, and the constitutive androstane receptor (CAR) (30-32). Thus, this study focused on the activity of the P450s in order to optimize hepatocyte functions.

AhR regulates hepatic detoxification at every level; however, the binding to an activating ligand is needed in order to exert its effects (33). Previous studies have demonstrated that AhR regulates all CYP450 enzymes that are also induced by aromatic hydrocarbons, such as TCDD (34-36) and 3-methylcholanthrene (3-MC) $(37,38)$. In agreement with previous observations in other cell types, our results indicated that ITE may efficiently enhance the activity of CYP450 enzymes without any observable toxic effect on liver cells. AhR is a cytosolic transcription factor that is normally inactive, bound to several co-chaperones. Upon binding to its ligands, including ITE, the chaperones dissociate, resulting in the translocation of AhR to the nucleus. This leads to the formation of a heterodimer with the closely-related ARNT nuclear protein (19,39). Accordingly, the AhR/ARNT complex can alter the transcription of the CYP1 enzymes and thereby increase CYP450 activity (40). Noticeably, ITE preferentially enhances the protein levels and metabolic activity of CYP3A4 in both monolayer culture and in alginate microspheres compared to other CYP450 family members. Paradoxically, the transcription levels of CYP3A4 were not markedly increased by ITE treatment in those settings. Thus, the molecular mechanisms underlying the effects of ITE on CYP3A4 warrant further investigation.

A previous study demonstrated that the expression levels of CYP450 may negatively correlate with the hepatocyte proliferation rate (4). Specifically, cells trapped in microspheres are not able to proliferate, possibly due to the structure of the gel itself and the minimal interactions with the matrix (41). These data are in agreement with other publications using alginate sponges as an approach to facilitate hepatocyte aggregation and the re-expression of differentiated functions 
$0.2 \mu \mathrm{M}$ ITE vs. $0 \mu \mathrm{M}$ ITE GO enrichment

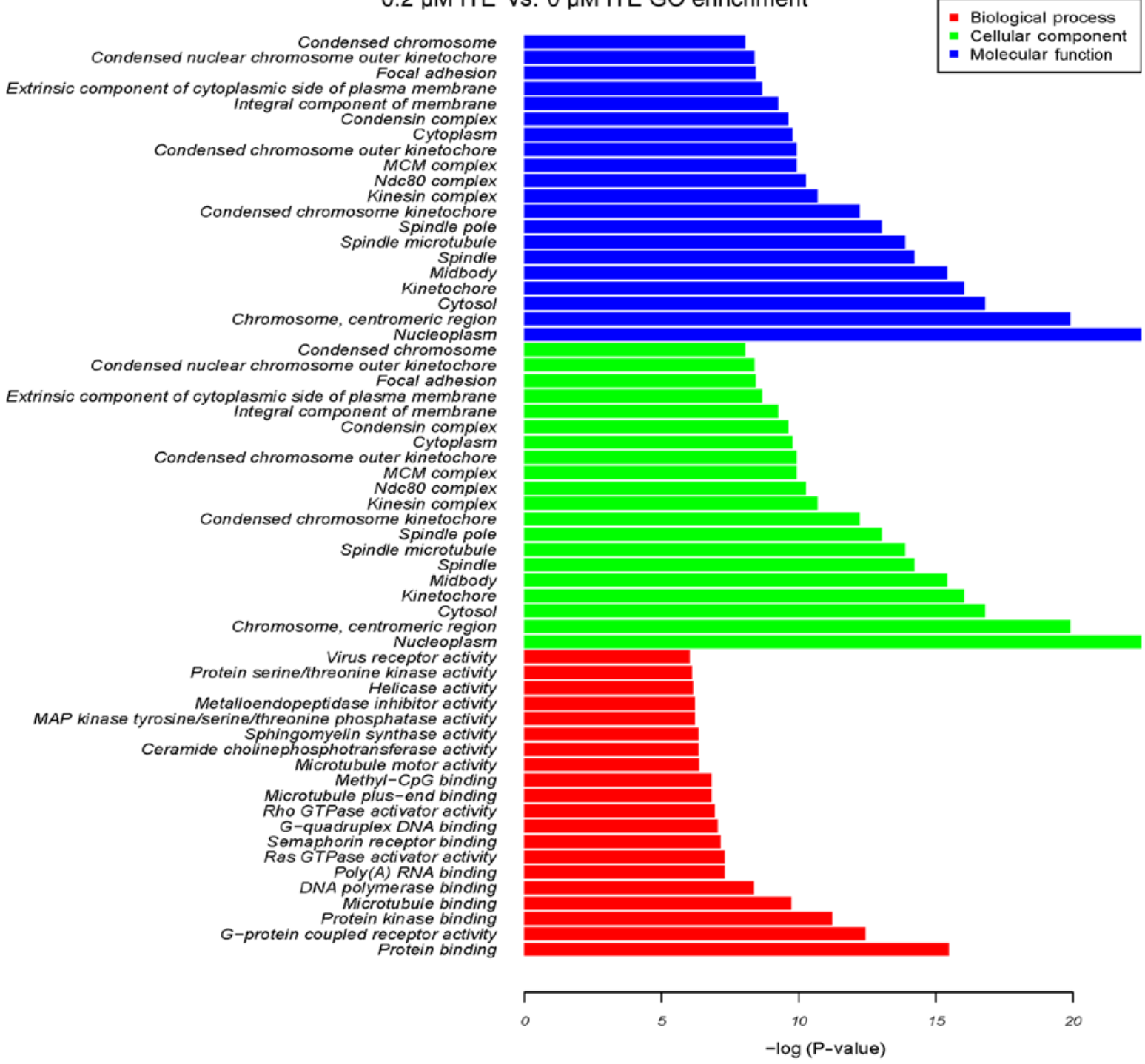

Figure 11. GO analysis for DNA microarray data on monolayer C3A cells treated with and without $0.2 \mu \mathrm{M}$ 2-(1'H-indole-3'-carbonyl)-thiazole-4-carboxylic acid methyl ester (ITE) for $48 \mathrm{~h}$.

prior to implantation (42). Therefore, we believe that one potential mechanism through which ITE regulates CYP450 activity is to reduce the interactions between the hepatocytes and the matrix via the microspheres. Under such conditions, the proliferation rate of hepatocytes is reduced compared to the activity of the CYP450 isoenzymes. Moreover, it has been demonstrated that AhR activation can lead to G0-G1 cell cycle arrest, a decreased capacity for DNA replication and to the inhibition of cell proliferation (43). On the other hand, the transcriptionally active AhR/ARNT heterodimer initiates gene transcription for many phase I drug metabolizing enzymes and several phase II conjugating enzymes, thus controlling the xenobiotic detoxification response $(19,44)$. Furthermore, it has been confirmed that augmenter of liver regeneration (ALR), a hepatotrophic factor, downregulates CYP450 in human liver, thereby linking growth signals with the regulation of hepatic metabolism (45). In addition, it has been demonstrated that polychlorinated biphenyls (PCBs) used as AhR agonists lead to cell proliferation associated with the mRNA expression of CYP450 1A1 (46). This suggests that there is an association between cell cycle regulation and CYP450 induction by AhR ligands, such as ITE. Our assumption was supported by the results of DNA microarray (Figs. 9-11), which indicated that the presence of ITE in the culture medium may have inhibited the cell cycle progression of hepatocytes, while promoting their CYP450 activities.

In contrast to conventional monolayer culture, artificial constructs of 3D multi-cellular spherical aggregates manifest a high degree of cell-cell contact, which is of the utmost importance for the communication signals necessary for coordinating and integrating gene expression patterns (47). Indeed, 3D aggregates closely resemble the in vivo situation regarding cell shape and cellular environment (48), which can in turn regulate gene expression and enhance the biological behavior of cells (49). Moreover, spherical microcapsules offer optimal surface-to-volume ratio for protein and nutrient diffusion as well as cell viability. 3D aggregates allow cell survival along with protein secretion activity upon appropriate host stimuli, without the deleterious effects of immunosuppressant drugs (31). This study confirmd that the 
treatment of 3D cultures of $\mathrm{C} 3 \mathrm{~A}$ cells/Huh7 cells with ITE improved the CYP activity of these organotypic liver tissue structures. This is of utmost importance for drug development and chemical testing. In fact, these 3D C3A cells/Huh7 cells spheroids with enhanced CYP activity may be of great value for the assessment of drug excretion to the bile, efflux transportermediated drug-drug interactions and toxicity of chemical compounds. Furthermore, among a multitude of techniques conceived and developed to generate $3 \mathrm{D}$ aggregates in vitro, the encapsulation of cells within the confines of semi-permeable membranes is likely to become a promising method for cell transplantation therapies and BALs (50). Thus, it is necessary to further investigate the effects of ITE administration in microsphere cultures of hepatocytes in a bioreactor. In the present study, we found that the presence of ITE in culture increased CYP450 activities and functional gene expression, indicating that ITE is a novel promoting factor for future clinical application of BALs to improve metabolic functions of hepatocytes in microspheres.

In addition, it is acknowledged that the microsphere diameter may affect the properties and/or biological characteristics of cells (51). In our previous studies $(4,52)$, we evaluated the permeability and viability of hepatocytes in microspheres of different diameters (300 and $800 \mu \mathrm{m}$ ). However, no significant differences between these two diameters were found. Moreover, it has been shown that large microsphere diameters can offer favorable permeability and maintain cell viability by improving the exchange of nutrients and growth factors (4). Furthermore, Gautier et al (53) also demonstrated that microspheres with a large diameter of $1,000 \mu \mathrm{m}$ provided a reliable entrapment process for hepatocytes to be used as a bioartificial liver. Accordingly microspheres with a diameter of $800 \mu \mathrm{m}$ were employed in our study.

Moreover, it is important to emphasize that the CYP450 activities were higher in monolayer culture than in microspheres in the presence of ITE. These results appear to contradict those of previous studies showing that microspheres providing 3D conditions exhibit enhanced functionality $(47,54,55)$. Such a paradox may be attributed to the hydrophobic properties of ITE. Furthermore, in the microsphere setting, substances first need to cross the alginate porous structure, where they have a lower diffusivity than that observed in saline solution (41). The lower diffusivity may result in the restricted and delayed transport of ITE from the supernatant to the inner bead, thus conferring a worse outcome for microspheres than for monolayer cultures. Of note, we found that albumin synthesis and urea synthesis in the $\mathrm{C} 3 \mathrm{~A}$ microspheres were higher than those observed in monolayer culture, which is in agreement with the findings of previous studies. Our explanation was that the lower diffusivity caused by microspheres cultured under static conditions may affect ITE efficiency; however, the synthesis functions which were a result of accumulation were free from the lower diffusivity. Therefore, further studies are required in order to investigate the effects of ITE administration in microsphere cultures of hepatocytes in a bioreactor to exclude the low diffusivity distraction.

In conclusion, in this study, we examined the effects of various concentrations of ITE on Huh7 and C3A cells cultured in a monolayer and on microspheres. Our data indicated that the addition of ITE to Huh7 and C3A cells in either a mono- layer or on microspheres significantly enhanced the protein levels and metabolic activities of the major CYP450 enzymes and the metabolic functions of Huh7 and C3A cells. Moreover, we verified that the improved metabolic functions of the liver cells are associated with the metabolism of xenobiotics via AhR-dependent signaling pathways. Taken together, the improvement of liver cell functions by ITE may be a promising approach for the treatment of liver diseases.

\section{Acknowledgements}

This study was financially supported by the National High Technology Research and Development Program of China (863 Program, grant nos. 2012AA020204 and 2013AA020102), the National Natural Science Foundation of China (grant no. 31271465), and the Zhejiang Provincial Natural Science Foundation of China for Distinguished Young Scholars (grant no. R2100226). We would like to thank Dr Jiasheng Song (AhR Pharmaceuticals, Inc.) for kindly providing the ITE, and Jianzhou Li and Yini Wang for general technical assistance and advice.

\section{References}

1. Bernal W and Wendon J: Acute liver failure. N Engl J Med 369: 2525-2534, 2013

2. Tostões RM, Leite SB, Miranda JP, Sousa M, Wang DI, Carrondo MJ and Alves PM: Perfusion of 3D encapsulated hepatocytes - a synergistic effect enhancing long-term functionality in bioreactors. Biotechnol Bioeng 108: 41-49, 2011.

3. Carpentier B, Gautier A and Legallais C: Artificial and bioartificial liver devices: present and future. Gut 58: 1690-1702, 2009.

4. Yang Y, Li J, Pan X, Zhou P, Yu X, Cao H, Wang Y and Li L: Co-culture with mesenchymal stem cells enhances metabolic functions of liver cells in bioartificial liver system. Biotechnol Bioeng 110: 958-968, 2013.

5. Chamuleau RA, Deurholt T and Hoekstra R: Which are the right cells to be used in a bioartificial liver? Metab Brain Dis 20: 327-335, 2005.

6. Nakamura T, Tomita Y, Hirai R, Yamaoka K, Kaji K and Ichihara A: Inhibitory effect of transforming growth factor-beta on DNA synthesis of adult rat hepatocytes in primary culture. Biochem Biophys Res Commun 133: 1042-1050, 1985.

7. Zanger UM, Turpeinen M, Klein K and Schwab M: Functional pharmacogenetics/genomics of human cytochromes P450 involved in drug biotransformation. Anal Bioanal Chem 392: 1093-1108, 2008 .

8. Gebhardt R, Hengstler JG, Müller D, Glöckner R, Buenning P, Laube B, Schmelzer E, Ullrich M, Utesch D, Hewitt N, et al: New hepatocyte in vitro systems for drug metabolism: metabolic capacity and recommendations for application in basic research and drug development, standard operation procedures. Drug Metab Rev 35: 145-213, 2003.

9. Gómez-Lechón MJ, Donato MT, Castell JV and Jover R: Human hepatocytes as a tool for studying toxicity and drug metabolism. Curr Drug Metab 4: 292-312, 2003.

10. Vermeir M, Annaert P, Mamidi RN, Roymans D, Meuldermans W and Mannens G: Cell-based models to study hepatic drug metabolism and enzyme induction in humans. Expert Opin Drug Metab Toxicol 1: 75-90, 2005.

11. Filippi C, Keatch SA, Rangar D, Nelson LJ, Hayes PC and Plevris JN: Improvement of C3A cell metabolism for usage in bioartificial liver support systems. J Hepatol 41: 599-605, 2004.

12. Sivertsson L, Ek M, Darnell M, Edebert I, Ingelman-Sundberg M and Neve EP: CYP3A4 catalytic activity is induced in confluent Huh7 hepatoma cells. Drug Metab Dispos 38: 995-1002, 2010.

13. Sussman NL, Gislason GT, Conlin CA and Kelly JH: The Hepatix extracorporeal liver assist device: initial clinical experience. Artif Organs 18: 390-396, 1994.

14. Ellis AJ, Hughes RD, Wendon JA, Dunne J, Langley PG, Kelly JH, Gislason GT, Sussman NL and Williams R: Pilot-controlled trial of the extracorporeal liver assist device in acute liver failure. Hepatology 24: 1446-1451, 1996. 
15. Hughes RD, Nicolaou N, Langley PG, Ellis AJ, Wendon JA and Williams R: Plasma cytokine levels and coagulation and complement activation during use of the extracorporeal liver assist device in acute liver failure. Artif Organs 22: 854-858, 1998

16. Tsay JJ, Tchou-Wong KM, Greenberg AK, Pass H and Rom WN: Aryl hydrocarbon receptor and lung cancer. Anticancer Res 33: 1247-1256, 2013.

17. Cheng J, Li W, Kang B, Zhou Y, Song J, Dan S, Yang Y, Zhang X, Li J, Yin S, et al: Tryptophan derivatives regulate the transcription of Oct 4 in stem-like cancer cells. Nat Commun 6 : 7209, 2015

18. Minsavage GD, Park SK and Gasiewicz TA: The aryl hydrocarbon receptor (AhR) tyrosine 9, a residue that is essential for AhR DNA binding activity, is not a phosphoresidue but augments AhR phosphorylation. J Biol Chem 279: 20582-20593, 2004.

19. Hankinson O: The aryl hydrocarbon receptor complex. Annu Rev Pharmacol Toxicol 35: 307-340, 1995.

20. Whitlock JP Jr: Induction of cytochrome P4501A1. Annu Rev Pharmacol Toxicol 39: 103-125, 1999.

21. Song J, Clagett-Dame M, Peterson RE, Hahn ME, Westler WM, Sicinski RR and DeLuca HF: A ligand for the aryl hydrocarbon receptor isolated from lung. Proc Natl Acad Sci USA 99: 14694-14699, 2002.

22. Khetani SR and Bhatia SN: Microscale culture of human liver cells for drug development. Nat Biotechnol 26: 120-126, 2008.

23. Isom HC, Secott T, Georgoff I, Woodworth C and Mummaw $\mathrm{J}$ : Maintenance of differentiated rat hepatocytes in primary culture. Proc Natl Acad Sci USA 82: 3252-3256, 1985.

24. Dich J, Vind C and Grunnet N: Long-term culture of hepatocytes: effect of hormones on enzyme activities and metabolic capacity. Hepatology 8: 39-45, 1988.

25. Kubota $\mathrm{H}$ and Reid LM: Clonogenic hepatoblasts, common precursors for hepatocytic and biliary lineages, are lacking classical major histocompatibility complex class I antigen. Proc Natl Acad Sci USA 97: 12132-12137, 2000.

26. Allen JW, Hassanein T and Bhatia SN: Advances in bioartificial liver devices. Hepatology 34: 447-455, 2001.

27. Guillouzo A, Corlu A, Aninat C, Glaise D, Morel F and Guguen-Guillouzo C: The human hepatoma HepaRG cells: a highly differentiated model for studies of liver metabolism and toxicity of xenobiotics. Chem Biol Interact 168: 66-73, 2007.

28. Nibourg GA, Huisman MT, van der Hoeven TV, van Gulik TM Chamuleau RA and Hoekstra R: Stable overexpression of pregnane $\mathrm{X}$ receptor in HepG2 cells increases its potential for bioartificial liver application. Liver Transpl 16: 1075-1085, 2010

29. Wang N, Tsuruoka S, Yamamoto H, Enosawa S, Omasa T, Sata N, Matsumura T, Nagai $\mathrm{H}$ and Fujimura A: The bioreactor with CYP3A4- and glutamine synthetase-introduced HepG2 cells: treatment of hepatic failure dog with diazepam overdosage. Artif Organs 29: 681-684, 2005.

30. Fujii-Kuriyama Y and Mimura J: Molecular mechanisms of AhR functions in the regulation of cytochrome P450 genes. Biochem Biophys Res Commun 338: 311-317, 2005.

31. Rabanel JM, Banquy X, Zouaoui H, Mokhtar M and Hildgen P Progress technology in microencapsulation methods for cell therapy. Biotechnol Prog 25: 946-963, 2009.

32. Jover R, Moya M and Gómez-Lechón MJ: Transcriptional regulation of cytochrome $\mathrm{p} 450$ genes by the nuclear receptor hepatocyte nuclear factor 4-alpha. Curr Drug Metab 10: 508-519, 2009

33. Puga A, Ma C and Marlowe JL: The aryl hydrocarbon receptor cross-talks with multiple signal transduction pathways. Biochem Pharmacol 77: 713-722, 2009.

34. Marie S, Anderson A and Cresteil T: Transplacental induction of cytochromes P-450IA1 and P-450IA 2 by polycyclic aromatic carcinogens: TCDD-binding protein level as the rate-limiting step. Carcinogenesis 9: 2059-2063, 1988.

35. Tritscher AM, Goldstein JA, Portier CJ, McCoy Z, Clark GC and Lucier GW: Dose-response relationships for chronic exposure to 2,3,7,8-tetrachlorodibenzo-p-dioxin in a rat tumor promotion model: quantification and immunolocalization of CYP1A1 and CYP1A2 in the liver. Cancer Res 52: 3436-3442, 1992.

36. Döhr O, Vogel C and Abel J: Different response of 2,3,7,8-tetrachlorodibenzo-p-dioxin (TCDD)-sensitive genes in human breast cancer MCF-7 and MDA-MB 231 cells. Arch Biochem Biophys 321: 405-412, 1995.
37. Gonzalez FJ, Tukey RH and Nebert DW: Structural gene products of the Ah locus. Transcriptional regulation of cytochrome P1-450 and P3-450 mRNA levels by 3-methylcholanthrene. Mol Pharmacol 26: 117-121, 1984

38. Goasduff T, Menez JF, Dreano Y and Berthou F: CYP1A 2 and 2E1 expression in rat liver treated with combined inducers (3-methylcholanthrene and ethanol). Biochem Biophys Res Commun 211: 497-503, 1995

39. Mimura J and Fujii-Kuriyama Y: Functional role of AhR in the expression of toxic effects by TCDD. Biochim Biophys Acta 1619: 263-268, 2003

40. Kinasiewicz A, Gautier A, Lewinska D, Bukowski J, Legallais C and Weryński A: Culture of C3A cells in alginate beads for fluidized bed bioartificial liver. Transplant Proc 39: 2911-2913, 2007.

41. David B, Dufresne M, Nagel MD and Legallais C: In vitro assessment of encapsulated C3A hepatocytes functions in a fluidized bed bioreactor. Biotechnol Prog 20: 1204-1212, 2004.

42. Glicklis R, Shapiro L, Agbaria R, Merchuk JC and Cohen S: Hepatocyte behavior within three-dimensional porous alginate scaffolds. Biotechnol Bioeng 67: 344-353, 2000.

43. Fan Y, Boivin GP, Knudsen ES, Nebert DW, Xia Y and Puga A: The aryl hydrocarbon receptor functions as a tumor suppressor of liver carcinogenesis. Cancer Res 70: 212-220, 2010.

44. Schnekenburger M, Peng L and Puga A: HDAC1 bound to the Cyplal promoter blocks histone acetylation associated with Ah receptor-mediated trans-activation. Biochim Biophys Acta 1769: 569-578, 2007.

45. Thasler WE, Dayoub R, Mühlbauer M, Hellerbrand C, Singer T, Gräbe A, Jauch KW, Schlitt HJ and Weiss TS: Repression of cytochrome $\mathrm{P} 450$ activity in human hepatocytes in vitro by a novel hepatotrophic factor, augmenter of liver regeneration. J Pharmacol Exp Ther 316: 822-829, 2006.

46. Vondrácek J, Machala M, Bryja V, Chramostová K, Krcmár P, Dietrich C, Hampl A and Kozubík A: Aryl hydrocarbon receptor-activating polychlorinated biphenyls and their hydroxylated metabolites induce cell proliferation in contact-inhibited rat liver epithelial cells. Toxicol Sci 83: 53-63, 2005.

47. Curcio E, Salerno S, Barbieri G, De Bartolo L, Drioli E and Bader A: Mass transfer and metabolic reactions in hepatocyte spheroids cultured in rotating wall gas-permeable membrane system. Biomaterials 28: 5487-5497, 2007.

48. Beningo KA, Dembo M and Wang YL: Responses of fibroblasts to anchorage of dorsal extracellular matrix receptors. Proc Natl Acad Sci USA 101: 18024-18029, 2004

49. Zhang X, Wang W, Yu W, Xie Y, Zhang X, Zhang Y and Ma X: Development of an in vitro multicellular tumor spheroid model using microencapsulation and its application in anticancer drug screening and testing. Biotechnol Prog 21: 1289-1296, 2005.

50. Orive G, Tam SK, Pedraz JL and Hallé JP: Biocompatibility of alginate-poly-L-lysine microcapsules for cell therapy. Biomaterials 27: 3691-3700, 2006

51. Neubauer MP, Poehlmann M and Fery A: Microcapsule mechanics: from stability to function. Adv Colloid Interface Sci 207: 65-80, 2014.

52. Lv G, Zhao L, Zhang A, Du W, Chen Y, Yu C, Pan X, Zhang Y, Song T, Xu J, et al: Bioartificial liver system based on choanoid fluidized bed bioreactor improve the survival time of fulminant hepatic failure pigs. Biotechnol Bioeng 108: 2229-2236, 2011

53. Gautier A, Carpentier B, Dufresne M, Vu Dinh Q, Paullier P and Legallais C: Impact of alginate type and bead diameter on mass transfers and the metabolic activities of encapsulated C3A cells in bioartificial liver applications. Eur Cell Mater 21: 94-106, 2011

54. Hoshikawa A, Nakayama Y, Matsuda T, Oda H, Nakamura K and Mabuchi K: Encapsulation of chondrocytes in photopolymerizable styrenated gelatin for cartilage tissue engineering. Tissue Eng 12: 2333-2341, 2006.

55. Bazou D, Coakley WT, Hayes AJ and Jackson SK: Long-term viability and proliferation of alginate-encapsulated 3-D HepG2 aggregates formed in an ultrasound trap. Toxicol In Vitro 22. $1321-1331,2008$ 